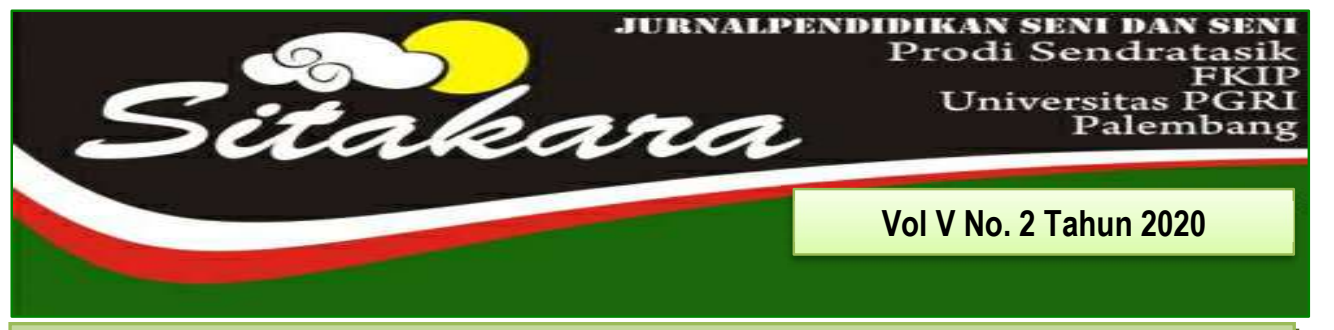

FUNGSI DAN MAKNA BHAJAN PADA UPACARA AGAMA HINDU DI KUIL SHRI MARIAMMAN KOTA MEDAN

(Agung Suharyanto, dkk)

KESENIAN SRANDUL DALAM UPACARA BERSIH DESA BULU KALURAHAN KARANGMOJO KECAMATAN KARANGMOJO KABUPATEN GUNUNGKIDUL YOGYAKARTA

(Supriyanto)

FUNGSI DAN MAKNA LAGU GUBANG DALAM UPACARA SIAR MAMBANG PADA MASYARAKAT TANJUNGBALAI

(Theo henry tua siagian ${ }^{1}$, pulumun p. Ginting ${ }^{2} \&$ wiflihani)

FUNGSI TARI MAPAK ADAT MUARA KUANG SEBAGAI TARI SAMBUT

(Nadia Rahma Aprilia', Dessy Wardiah², Treny Hera ${ }^{3}$ )

MAKNA SIMBOLIK RAGAM HIAS PADA RUMAH LIMAS PALEMBANG

(Ferri Hidayad ${ }^{1}$ Decky Kunian ${ }^{2}$ )

GAYA MUSIK SAHILIN DALAM KESENIAN MUSIK BATANGHARI SEMBILAN DI KOTA PALEMBANG

(Feri Firmansyah)

TRANSPOSISI TTI (TRANSFER, TRANSLATION, IMITATE) DALAM PEMBELAJARAN NOTASI MUSIK MELALUI SCORE CREATOR

(A Heryanto ${ }^{1}$ Dedy Firmansyah ${ }^{2}$ )

RASE TAK SERUPE MUSIK MELAYU TRADISI DENGAN PENGEMBANGAN MUSIK MODERN DALAM RUANG PERTUNJUKAN KOMPOSISI MUSIK NUSANTARA (Rio Eka Putra)

BENTUK SYAIR LAGU DALAM PERTUNJUKAN SYAROFAL ANAM DI PEDESTRIAN S UDIRMAN KOTA PALEMBANG

(Nofroza Yelli ${ }^{1}$ Deria Sepdwiko² ${ }^{2}$

"Betenun" Sebuah Wujud Proses Kreatif Mahasiswa Seni Pertunjukan Universitas PGRI PALEMBANG

(Nurdin $^{1}$ Naomi Diah Budi Setyaningrum ${ }^{2}$ ) 
DAFTAR ISI

FUNGSI DAN MAKNA BHAJAN PADA UPACARA AGAMA HINDU DI KUIL 1-15 SHRI MARIAMMAN KOTA MEDAN

(Agung Suharyanto, dkk)

KESENIAN SRANDUL DALAM UPACARA BERSIH DESA BULU KALURAHAN

$16-26$

KARANGMOJO KECAMATAN KARANGMOJO KABUPATEN GUNUNGKIDUL YOGYAKARTA

(Supriyanto)

FUNGSI DAN MAKNA LAGU GUBANG DALAM UPACARA SIAR MAMBANG 27-39 PADA MASYARAKAT TANJUNGBALAI

(Theo henry tua siagian ${ }^{1}$, pulumun $p$. Ginting ${ }^{2} \&$ wiflihani)

FUNGSI TARI MAPAK ADAT MUARA KUANG SEBAGAI TARI SAMBUT

40-52

(Nadia Rahma Aprilia', Dessy Wardiah², Treny Hera')

MAKNA SIMBOLIK RAGAM HIAS PADA RUMAH LIMAS PALEMBANG

53-61

(Ferri Hidayad ${ }^{1}$ Decky Kunian ${ }^{2}$ )

GAYA MUSIK SAHILIN DALAM KESENIAN MUSIK BATANGHARI SEMBILAN DI $\quad 62-76$ KOTA PALEMBANG

(Feri Firmansyah)

TRANSPOSISI TTI (TRANSFER, TRANSLATION, IMITATE) DALAM 77-85 PEMBELAJARAN NOTASI MUSIK MELALUI SCORE CREATOR (A Heryanto ${ }^{1}$ Dedy Firmansyah ${ }^{2}$ )

RASE TAK SERUPE MUSIK MELAYU TRADISI DENGAN PENGEMBANGAN MUSIK MODERN DALAM RUANG PERTUNJUKAN KOMPOSISI MUSIK NUSANTARA

(Rio Eka Putra)

BENTUK SYAIR LAGU DALAM PERTUNJUKAN SYAROFAL ANAM DI PEDESTRIAN SUDIRMAN KOTA PALEMBANG

(Nofroza Yelli ${ }^{1}$ Deria Sepdwiko ${ }^{2}$ )

"BETENUN" SEBUAH WUJUD PROSES KREATIF MAHASISWA SENI

$109-120$ PERTUNJUKAN UNIVERSITAS PGRI PALEMBANG

(Nurdin ${ }^{1}$ Naomi Diah Budi Setyaningrum ${ }^{2}$ )

86-95 


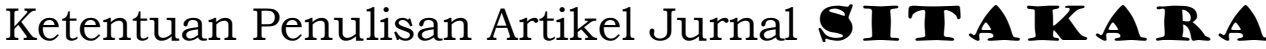

1. Naskah berbahasa Indonesia bertemakan Seni Budaya yang meliputi hasil penelitian pengajaran seni budaya, cabang seni, dan kebudayaan.

2. Naskah harus asli dan belum pernah dimuat dalam media lain. Naskah dapat berupa hasil penelitian perorangan atau kelompok.

3. Naskah ditulis dengan cara-cara yang sesuai dengan ketentuan penulisan artikel ilmiah menggunakan bahasa Indonesia yang baku, berupa ketikan, beserta soft line dalam CD-RW atau dengan mengirimkan email pada redaksi Jurnal SITAKA RA dengan alamat email: jurnalsitakarasendratasik@yahoo.com, spasi 1,5 jenis huruf Arrial Narrow ukuran 12, dengan panjang naskah antara 8-15 halaman pada kertas A4.

4. Artikel hasil penelitian memuat:

JUDUL

Nama Penulis

Abstrak

A. PENDAhuluan

B. METODE PENELITIAN

C. HASIL DAN PEMBAHASAN

D. SIMPULAN

5. Artikel kajian konseptual memuat:

JUDUL

Nama Penulis

Abstrak

PENDAHULUAN
: XXX (HURUF KAPITAL)

: (disertai jabatan dan institusi)

: (Bahasa Indonesia yang memuat 100150 kata diikuti kata kunci, dengan jenis huruf Arrial Narrow dan ukuran huruf 11 spasi tunggal serta dicetak miring)

: (Memuat latar belakang masalah, tinjauan pustaka secara ringkas, masalah penelitian dan tujuan penelitian)

: (Berisi simpulan)

\section{: XXX (HURUF KAPITAL)}

: (disertai jabatan dan institusi)

: (Bahasa Indonesia yang memuat 100150 kata diikuti kata kunci, dengan jenis huruf Arrial Narrow dan ukuran huruf 11 serta dicetak miring)

: (Memuat latar belakang masalah, tinjauan pustaka secara ringkas, 
Sub Judul

Sub Judul

SIMPULAN

DAFTAR PUSTAKA masalah penelitian dan tujuan

penelitian)

: Sesuai dengan kebutuhan (tanpa

numbering)

: (Berisi simpulan dan saran)

: (Berisi pustaka yang dirujuk dalam uraian naskah

6. Referensi sumber dalam teks artikel ditulis dengan menggunakan side note, contoh: (Jalalluddin, 1991:79); (Taufik, 2005;350); (Hamid dan Madjid, 2011:43). Sementara penulisan daftar pustaka disusun dengan ketentuan. Nama Pengarang. Tahun Terbit. Judul (dicetak miring). Kota Terbit: Nama Penerbit. Contoh: Koentjaraningrat. 2010. Manusia dan Kebudayaan Di Indonesia. Jakarta: Djambatan.

Daftar pustaka hanya memuat pustaka/sumber yang dirujuk dalam uraian dan disusun menurut abjad, tanpa nomor urut.

7. Naskah yang dimuat akan disunting kembali oleh redaksi tanpa mengubah isinya.

8. Naskah yang ditolak (tidak bisa dimuat) akan dikirim kembali ke penulis dengan pemberitahuan tertulis dari redaksi atau alamat email.

9. Penulis yang naskahnya dimuat akan mendapatkan 1 (satu) majalah nomor yang bersangkutan.

10. Contact Person: Treny Hera (085357344704) dan Mainur (081373165553). 


\title{
BENTUK SYAIR LAGU DALAM PERTUNJUKAN SYAROFAL ANAM DI PEDESTRIAN SUDIRMAN KOTA PALEMBANG
}

\author{
Oleh: \\ Nofroza Yelli ${ }^{1}$ Deria Sepdwiko ${ }^{2}$ \\ (FKIP Universitas PGRI Palembang) \\ Email: yelliumboro@gmail.com
}

\begin{abstract}
ABSTRAK
Penelitian ini bertujuan untuk menyajikan kesenian Syarofal Anam dengan sruktur lagu yang lebih menarik tanpa merobah bentuk aslinya, dan juga memberikan kesadaran kepada masyarakat agar terus mencintai dan melestarikan seni tradisi Sumatera Selatan khususnya Syarofal Anam. Penelitian ini menggunakan metode penelitian kualitatif, dimana data penelitian dikumpulkan melalui Teknik observasi, wawancara dan dokumentasi. Observasi dilakukan ke lokasi penelitian yaitu Pedestrian Sudirman kota Palembang dan lokasi kelompok musik Syarofal Anam di Pesantren Sabulussalam. Dokumentasi diambil melalui pengambilan video dan foto kesenian Syarofal Anam mulai dari proses latihan hingga pertunjukan. Wawancara dilakukan guna mengetahui informasi penting terkait pertunjukan Syarofal Anam di pedestrian Sudirman kota Palembang. Hasil penelitian didapat bahwa terdapat struktur penyajian lagu yang berbeda dengan kesenian Syarofal Anam yang dipertunjukan dalam acara pernikahan atau acara akikah. Dimana pada acara hiburan yang disajikan di Pedestrian Sudirman ini, terdapat lagu-lagu populer di Indonesia saat ini, guna menarik perhatian penonton, sehingga kesenian tradisi Syarofal Anam ini terus dikenal oleh masyarakat kota Palembang khususnya.
\end{abstract}

Kata kunci: Syair lagu, kesenian Syarofal Anam, Pedestrian Sudirman.

\section{A. PENDAHULUAN}

Warisan budaya yang ada di kota Palembang sangat beragam. Mulai dari Bahasa, kuliner, hingga seni tradisi.

Seni tradisi yang berkembang di kota Palembangpun sangat beragam, mulai dari tari, teater, seni rupa dan seni musik. Kesenian Syarofal Anam merupakan salah satu seni tradisi di Kota Palembang yang tergolong kepada seni musik. Hal ini dikarenakan kesenian Syarofal Anam menghasilkan alunan suara atau nyanyian yang diiringi dengan pola tabuhan alat musik rebana atau yang biasa disebut terbangan. Seni tradisi Syarofal Anam sering ditampilkan dalam berbagai acara hiburan seperti acara pernikahan, dan juga hiburan di suatu tempat wisata di kota Palembang.

Salah satu lokasi wisata yang tergolong baru hadir di kota Palembang adalah Pedestrian Sudirman. Tempat ini diperuntukan oleh dinas Pariwisata Kota Palembang untuk masyarakat yang mempunyai keahlian tertentu, termasuk berkesenian. Pada tempat ini, seniman- 
seniman khususnya yang ada di kota

Palembang bisa menyajikan berbagai karya-karya mereka di hadapan khalayak ramai. Karena di tempat ini selalu ramai oleh pengunjung yang ingin menyaksikan berbagai macam bentuk kesenian, mulai dari seni tradisi hingga seni modern.

Kelompok seni Syarofal Anam yang akan diuraikan dalam penelitian ini yaitu kelompok musik Syarofal Anam di Pesantren Sabulussalam. Kelompok musik ini beralamat di Banten IV, 16 ulu Kota Palembang. Kelompok musik memiliki anggota 20 orang. Semua anggota adalah perwakilan dari siswa SMP dan SMA Pesantren Sabulussalam. Grup musik di pesantren ini sebelumnya sering mengisi acara hiburan pernikahan, maulid nabi SAW dan acara akikah. Lagu yang dibawakan dalam acara tersebut pada umumnya berisi salawat nabi dan barzanji. Pada penelitian ini grup Syarofal Anam ini menyajikan sebuah seni tradisi Syarofal Anam di Pedestrian Sudirman kota Palembang. Lagu yang dibawakan sedikit dikembangkan dengan menambahkan beberapa irama lagu religi yang saat ini sedang populer di Indonesia. Dengan harapan kesenian ini menjadi lebih kenal dan diminati dari sebelumnya. Penelitian ini bertujuan untuk mendeskripsikan bentuk syair lagu dalam pertunjukan Syarofal Anam di Pedestrian Sudirman kota Palembang, dengan menyajikan kesenian Syarofal Anam dengan sruktur lagu yang lebih menarik tanpa merobah bentuk aslinya. Selain itu, memberikan kesadaran kepada masyarakat agar terus mencintai dan melestarikan seni tradisi Sumatera Selatan khususnya kesenian Syarofal Anam.

Pembahasan dalam penelitian ini yaitu mengenai salah satu seni tradisi yang ada di Kota Palembang yang bernama kesenian Syarofal Anam. Pada penelitian ini diperlukan teori-teori terkait untuk memperkuat tulisan khsusnya dalam menguraikan Bentuk Syair Lagu Dalam Pertunjukan Syarofal Anam Di Pedestrian Sudirman Kota Palembang. Beberapa teori terkait yaitu menguraikan tentang; Bentuk syair lagu, pertunjukan, syarofal anam, pedestrian Sudirman kota Palembang.

1. Bentuk syair lagu

Pada artian luas, bentuk syair merupakan ungkapan pikiran atau perasaan yang popular dalam masyarakat melayu (Rukmi, 2005:159). Syair adalah bentuk puisi dalam sastra 
melayu lama. Kata syair berasal dari Bahasa Arab yaitu "Syu'ur" yang berarti perasaan, "syi'ru" yang berarti puisi dalam pengertian umum. Walaupun berasal dari Bahasa Arab, syair tidak tumbuh dalam ciri khas Arab, namun berkembang menjadi khas melayu (Hermansyah dan Zulkhairi, 2014:30). Lagu merupakan sebuah syair dengan tema tertentu yang diucapkan dengan menggunakan nada tertentu (Anam, 2011:96). Lagu dihasilkan dari suara yang memiliki irama dan pada umumnya disertakan dengan lirik yang berisikan tentang ungkapan perasaan dari penciptanya. Bentuk syair lagu yang akan dibahas dalam penelitian ini yakni peneliti akan mendeskripsikan uraikan lirik lagu yang di bawakan dalam kesenian Syarofal anam yang di pertunjukan di pedestrian Sudirman kota Palembang.

\section{Pertunjukan}

Seni pertunjukan merupakan bagian dari sejarah dan kebudayaan Indonesia, yang terdiri menjadi beberapa bagian yaitu, seni tari, seni musik, seni teater, sastra lisan, wayang, sirkus, opera, drama musikal, pantomim, sulap, dan musikalisasi puisi, (Bekraf 2015, dalam Dukut, 2020:140). Pertunjukan adalah kegiatan mempertunjukan kesenian, seperti kesenian tari, musik dan sebagainya. (Nakagawa, 2000:60). Menurut Iskandar 2006 (dalam Dukut, 2020:140), seni pertunjukan merupakan seni menyampaikan gagasan kepada penonton dengan mengolah ide ke bentuk lisan, musik, tata rupa, ekspresi dan gerakan tubuh secara langsung di dalam ruang dan waktu yang sama oleh pekerja teknis dan penampil.

3. Syarofal Anam

Kesenian syarofal anam adalah sebuah seni musik yang menyajikan vocal salawat atau puji-pujian kepada nabi Muhammad SAW yang di iringi dengan permainan alat musik terbangan. Setiap salawat yang dilantunkan kan akan diiringi oleh pukulah pola alat musik terbangan. Kesenian ini dimainkan oleh 10 hingga 16 orang yang masih-masih berperan sebagai pemain terbangan, dan dua di antaranya sebagai pelantun vocal (Hadi).

Berdasarkan bentuk penyajiannya, kesenian syarofal anam terbagi menjadi 3 bentuk, diantaranya: (Misral, dkk, 2014: 11-12)

a) Syarofal anam yang disajikan secara tunggal, tanpa disertai penyajian seni lainnya. Pada 
penyajian ini hanya terdiri dari

pembawa hadi yang

membawakan salawatan dan

pemain terbangan.

b) Syarofal anam yang disajikan terdiri dari kelompok musik syarofal anam (hadi dan pemain terbangan) dan kelompok rodat tegak (berjalan). Rodat tegak atau berjalan adalah penyajian sekelompok yang membentuk gerakan sambal berjalan. Rodat disebut juga dengan tari rodat, karena disajikan oleh sekelompok orang dengan membentuk gerakan tari. Bentuk seperti ini biasanya di tampilkan dalam acara arak-arakan pengantin.

c) Syarofal anam yang disajikan terdiri dari kelompok musik syarofal anam (hadi dan pemain terbangan) dan kelompok rodat duduk. Apabila pada rodat berjalan sekelompok rodat membuat gerakan menarinya sambal berjalan, maka pada rodat duduk gerakan menarinya dalam posisi duduk. Biasanya bentuk Syarofal Anam ini disajikan di atas panggung atau dalam ruangan.

Secara keseluruhan, kesenian ini biasa ditampilkan dalam acara tradisi seperti pernikahan, sunatan dan sebagainya. Pada kesempatan ini, penelitian ini akan melihat kesenian disajikan dalam konteks acara hiburan di pedestrian Sudirman kota palembang.

4. Pedestrian Sudirman Kota Palembang

Pedestrian Sudirman adalah sebuah lokasi wisata malam yang di sediakan oleh dinas pariwisata kota Palembang. Pedestrian Sudirman di buka setiap sabtu malam jam 19.0024.00 WIB. Dilokasi ini, masyarakat bisa menikmati berbagai macam ajang kreativitas khususnya bagi senimanseniman kota Palembang untuk menunjukan bakat masing-masing. Selain itu masyarakat bisa menikmati berbagai kuliner murah meriah yang di jual di lokasi tersebut sambil menikmati berbagai hiburan disana.

Pada awalnya pedestrian Sudirman hanya trotoar jalan biasa yang terdapat di sepanjang jalan Sudirman kota Palembang. Pada tahun 2017, lokasi jalan ini di tutup, karena proses pembangunan jalur LRT. Penutupan 
jalan ini dimanfaatkan oleh para anak muda sebagai tempat berkumpul hingga berunjuk bakat hingga menjadi ramai. Keramaian ini juga dimanfaatkan oleh para pedagang untuk berjualan disana. Setelah pembangunan LRT selesai dan trotoar disepanjang jalan ini juga di perbaiki dan di perluas. Maka dinas pariwisata meneruskan aktifitas di lokasi ini dengan menutup jalur ini satu kali seminggu yaitu pada malam minggu jam 19.00-24.00

WIB. (https://www.genpi.co/berita/9117/menik mati-wisata-malam-pedestrian-sudirmanpalembang, Diakses tanggal 20 Juli 2020.) Hingga saat ini, pedestrian Sudirman manjadi salah satu lokasi wisata malam di kota Palembang.

\section{B. METODE PENELITIAN} Metode penelitian yang digunakan adalah metode kualitatif dengan Teknik pengumpulan data observasi, wawancara, dan dokumentasi. Setelah didapatkan data yang cukup maka data tersebut diolah untuk kemudian dituliskan secara rinci dan jelas dalam bentuk diskriptif. Menentukan metode penelitian ini dilakukan dengan sangat selektif karena tidak semua metode penelitian dapat diterapkan dalam penelitian ini. Metode penelitian ini diharapkan dapat memenuhi kebutuhan penelitian dengan baik.

a. Observasi

Metode observasi adalah metode yang digunakan untuk mengamati sesuatu, seeorang, suatu lingkungan atau situasi secara tajam terinci dan mencatatnya secara akurat dalam berbagai cara. Metode observasi dalam penelitian seni dilaksanakan untuk memperoleh data tentang karya seni dalam suatu kegiatan dan situasi yang relevan dengan masalah penelitian (Rohidi.2011:182).

\section{b. Wawancara}

Wawancara adalah suatu teknik yang digunakan untuk memperoleh informasi

tentang kejadian yang diperoleh peneliti tidak dapat diamati sendiri secara langsung, baik karena tindakan atau peristiwa yang terjadi di masa lampau ataupun karena peneliti tidak diperbolehkan hadir di tempat kejadian itu (Rohidi. 2011:208). Wawancara dilakukan untuk memperoleh data-data secara langsung dari sumber yang mengetahui lokasi penelitian. Nara sumber pada penelitian ini yaitu Muhammad Ibnu yang merupakan guru 
sekaligus pelatih musik Syarofal Anam di

Pondok Pesantren Salubussalam kota Palembang.

\section{c. Metode Dokumentasi}

Data dokumentasi yang diambil pada penelitian ini yaitu berupa foto, video, dan audio. Foto adalah teknologi untuk menangkap dan menghasilkan suatu gambaran statis, diam tak bergerak, tentang suatu objek, orang atau pelaku, dan lingkungan, yang mampu memberikan bukti kuat mengenai suatu tampilan yang bermakna mengenai hal tertentu, berkaitan dengan permasalahan dalam penelitian (Rohidi. 2011: 195). Data video merupakan piranti yang kuat untuk menelaah peristiwa-peristiwa yang terjadi (Rohidi.2011: 198). Pengumpulan data video dirasa cukup menarik karena seiring dengan kemajuan jaman banyak hal yang dapat dimanfaatkan dalam bidang teknologi. Selanjutnya pengumpulan data audio yang digunakan selain untuk membantu observasi dalam merekam tindakan secara alamiah, baik dalam bentuk ungkapan verbal biasa maupun ungkapan yang spontan, juga dapat melengkapi catatan-catatan wawancara. Dengan menggunakan teknik audio peneliti dapat melengkapi jawaban yang tidak sempat ditulis yaitu dengan cara memutar kembali hasil rekaman yang telah dilakukan. Selain itu juga, peneliti dapat membayangkan kembali komunikasi yang telah dilakukan, merasakan suasananya, dan meresapi hubungan empati yang terjadi pada waktu wawancara (Rohidi.2011:202). Berbagai teknik pengumpulan data tersebut dilakukan agar dalam penelitian ini dapat secara tepat mengumpulkan data-data yang dibutuhkan dan akurat.

\section{HASIL DAN PEMBAHASAN}

Pedestrian terdapat di pelantaran jalan Sudirman kota Palembang. Jalan Sudirman membentang ditengan kota Palembang, mulai dari samping masjid agung kota Palembang, sampai ke daerah alangalang lebar Kota Palembang. Sepanjang jalan ini dipenuhi bangunan-bangunan pertokoan, perkantoran, sekolah, tempat ibadang, mall, hingga hotel dan rumah makan sebagaimana umumnya di kota besar. Sedangkan Pedestrian Sudirman yang menjadi lokasi wisata malam kota Palembang terdapat di daerah Cinde kota Palembang. Tempat ini mulai dijadikan tempat wisata malam kota 
Palembang sejak tahun 2017 sampai sekarang. Pada dasar nya tempat ini hanyalah trotoar yang terdapat di depan bagunan pertokoan yang aktif sebagaimana biasanya di siang hari. Tempat ini aktif satu kali dalam seminggu yaitu pada hari sabtu mulai dari jam 19.00 WIB sampai jam 24.00 WIB.

Para seniman memanfaatkan tempat ini sebagai ajang kreatifitas, dan para pedagang juga hadir untuk menjual berbagai makanan. Tempat ini sangat ramai dikunjungi masyarakat mulai dari dewasa, remaja, hingga anak-anak. Baik untuk menikmati hiburan-hiburan yang disajikan disana ataupun hanya sekedar manikmati kuliner yang tersedia lengkap disana. Beberapa kreatifitas anak muda yang ditampilkan disana seperti tarian, band, peragaan kostum robot, hingga kesenian tradisi seperti rejung atau gitar tunggal.

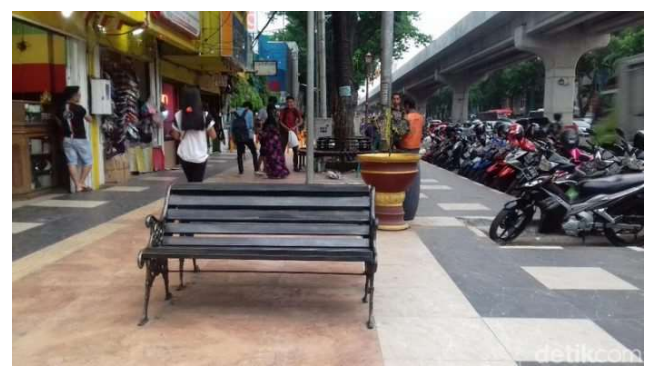

Gambar 1.

Jalan Sudirman dengan aktifitas pertokoan disiang hari (Dokumen: Nawacita, 2020)

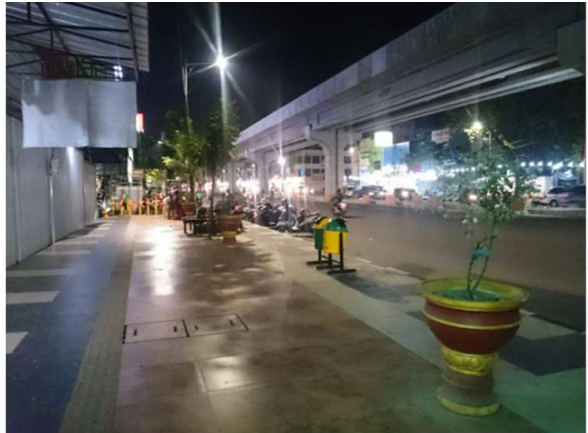

Gambar 2.

Jalan Sudirman di malam hari (Dokumen: Muhammad Fahmi, 2020)

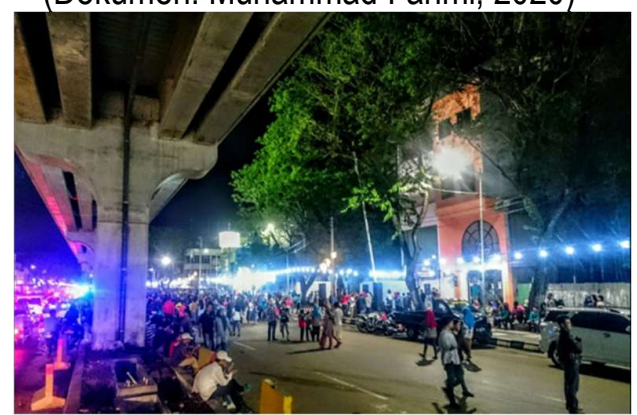

Gambar 3.

Pedestrian Sudirman sabtu malam (Dokumen: Muhammad Fahmi, 2020)

Observasi menjadi langkah awal dalam penelitian ini. Berawal dari ketertarikan peneliti mengenai salah satu tempat wisata yang sering mempergelarkan kesenian di kota Palembang yaitu Pedestrian Sudirman kota Palembang. Lokasi ini sebelumnya sering peneliti kunjungi. Saat ini, Pedestrian Sudirman menjadi salah satu tempat seniman berkreasi. Berbagai kesenian ditampilkan disana, mulai dari seni tari, seni musik, dan seni teater. Terkait hal ini, peneliti tertarik untuk 
menampilkan kesenian tradisi sumatera selatan di lokasi ini, yaitu kesenian Syarofal Anam. Dengan harapan, masyarakat tidak hanya bisa menyaksikan kesenian modern, namun juga seni tradisi, yang seharusnya memang di lestarikan dan dikembangkan kepada mastarakat luas saat ini.

Dari ide ini, peneliti memilih kelompok musik Syarofal Anam di pesantren Sabulussalam kota Palembang. Kelompok musik ini biasanya tampil pada acara hiburan pernikahan, maulid nabi SAW dan acara akikah. Pada penelitian ini, kelompok musik ini menyajikan musik Syarofal Anam di Pedestrian Sudirman kota Palembang. Materi yang disajikan di tempat ini tidak hanya lagu arab yang berisikan salawat nabi dan barzanji, sebagaimana yang biasanya di bawakan pada acara hiburan pernikahan atau akikah. Materi lagu yang dibawakan di lokasi ini ditambahkan dengan beberapa lagu popular saat ini seperti lagu yang berjudul "Aisyah Istri Rasululah" yang sedang populer saat ini di Indonesia. Pengembangan materi lagu ini bertujuan untuk menambah daya Tarik dari kesenian ini, agar masyarakat lebih menyukai kesenian tradisi Syarofal Anam.

\section{Bentuk Syair Syarofal Anam di Pedestrian Sudirman}

a). Salawat pembuka

Salawat pembuka ini biasanya dibawakan setiap awal pertunjukan Syarofal Anam yang berisikan kalimat "Allahumma Shali Wasalim Wabarik 'alaihi'. Kalimat ini dibacakan oleh Hadi (pelantun lagu dalam kesenian Syarofal Anam) dan kemudian diikuti oleh pemain terbangan secara Bersama-sama.

b). Salawat Ya Robbi Sholli Ala Muhammad

Ya robbi shalli ‘ala Muhammad

Ya robbi shalli 'alayhi wasallim

Ya robbi balllighul wasiilah

Ya robbi khusshoh bilfadliilah

Ya robbi wardlo 'anisshohaabah

Ya robbi wardlo 'anis-sulaalah

Ya robbi wardlo anil-masyaayikh

Ya robbi farham waalidiinaa

Ya robbi warhamnaa jamii'an

Ya robbi warham kulla muslim

Ya robbi waghfir likulli mudznib

Ya robbi laa taqtho' rojaanaa

Ya robbi yaa saami' du'aanaa

Ya robbi ballighnaa nazuuruh 


\begin{tabular}{|c|c|c|}
\hline Ya robbi taghsyaanaa binuurih & \multicolumn{2}{|c|}{ Dia Aisyah, putri Abu bakar } \\
\hline Ya robbi hifdhoonaka wa & \multicolumn{2}{|c|}{ Istri Rasulullah } \\
\hline amaanak & \multicolumn{2}{|c|}{ Sungguh sweet Nabi mencintamu } \\
\hline Ya robbi waskinnaa jinaanak & \multicolumn{2}{|c|}{ Hingga Nabi minum di bekas bibirmu } \\
\hline Ya robbi ajirnaa min ‘adzaabik & \multicolumn{2}{|c|}{ Bila marah, Nabi 'kan bermanja } \\
\hline Ya robbi & \multicolumn{2}{|c|}{ Mencubit hidungnya } \\
\hline warzuqnaasysyahaadah & \multicolumn{2}{|c|}{ Aisyah, romantisnya cintamu dengan } \\
\hline Ya robbi hithnaa bissa'aadah & \multicolumn{2}{|c|}{ Nabi } \\
\hline Ya robbi washlih kulla mushlih & \multicolumn{2}{|c|}{ Dengan baginda kau pernah main lari-lari } \\
\hline Ya robbi wakfi kulla mu,dzii & \multicolumn{2}{|c|}{ Selalu bersama } \\
\hline Ya robbi nakhtim bilmusyaffa' & \multicolumn{2}{|c|}{ Hingga ujung nyawa kau di samping } \\
\hline Ya robbi shalli ‘alaihi wa sallim & \multicolumn{2}{|c|}{ Rasulullah } \\
\hline & \multicolumn{2}{|c|}{ Aisyah, sungguh manis, oh sirah kasih } \\
\hline Salawat Man Ana & \multicolumn{2}{|c|}{ cintamu } \\
\hline Man Ana, Man Ana, Man Ana & \multicolumn{2}{|c|}{ Bukan persis novel mula benci jadi rindu } \\
\hline Laulakum & \multicolumn{2}{|c|}{ Kau istri tercinta, ya Aisyah Khumaira } \\
\hline Kaifa Ma Hubbukum Kaifa Ma & \multirow{2}{*}{\multicolumn{2}{|c|}{ Rasul sayang rasul kasih cintamu. }} \\
\hline Ahwakum & & \\
\hline Ma Siwaya Wa La Ghoirokum & & Salawat Ya Maulana \\
\hline Siwakum & & Dengan kasih-Mu Ya Rabbi \\
\hline La Wa Man Fil Mahabbah & & berkahi hidup ini \\
\hline 'Alayya Walakum & & Dengan cinta-Mu Ya Rabbi \\
\hline Antum Antum Murodi Wa Antum & & damaikan mati ini \\
\hline Qoshdi & & Saat salah ku melangkah \\
\hline Laisa Ahad Fil Mahabbah & & gelap hati penuh dosa \\
\hline Siwakum 'Indi & & $\begin{array}{l}\text { Beri ku jalan berarah } \\
\text { temui-Mu di Surga }\end{array}$ \\
\hline Salawat lagu Aisyah Istri & & Terima sembah sujudku \\
\hline & & terimalah doaku \\
\hline , cantik bers & & Terima sembah sujudku \\
\hline ersih, mer & & izinkan ku bertaubat \\
\hline
\end{tabular}


Maulana ya Maulana Yasami'

du'aana

Maulana ya Maulana Yasami'

du'aana

Saat salah ku melangkah

gelap hati penuh dosa

Beri ku jalan berarah

temui-Mu di Surga

Terima sembah sujudku

terimalah doaku

Terima sembah sujudku

izinkan ku bertaubat

f). Salawat penutup

Salawat penutup sama dengan salawat pembuka, yakni Hadi melantunkan kalimat "Allahumma Shali Wasalim Wabarik 'alaihi" dan kemudian diikuti oleh pemain terbangan secara Bersama-sama.

\section{Alat musik}

Alat musik yang digunakan dalam kesenian Syarofal Anam tergolong jenis alat musik perkusi yang dimainkan dengan cara di tepuk. Bagi masyarakat Sumatera Selatan pada umumnya, alat musik ini disebut dengan terbangan. Alat musik ini terbuat dari kayu dan kulit binatang, serta lempengan bulat yang terbuat dari kuningan yang terdapat pada sisi terbangan (Misral, 2014:15-16), sebagaimana pada gambar berikut.

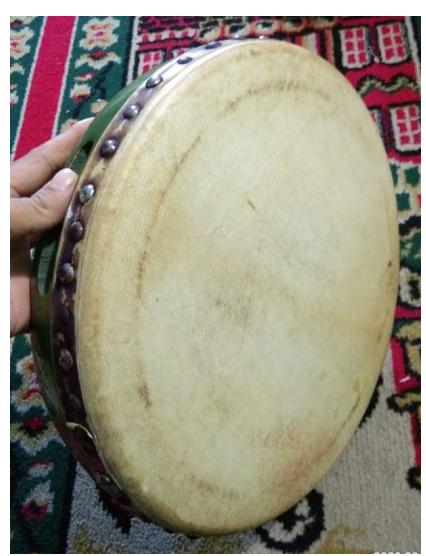

Gambar 4.

Alat musik terbangan

(Dokumen: Nofroza Yelli, 2020)

Alat musik yang digunakan pada pertunjukan Syarofal Anam pada berjumlah 10-16 buah sesuai dengan jumlah pemain. Masing-masing alat musik akan dibagi menjadi beberapa bagian, dengan pola pukulan yang juga berbeda. Pola dasar disebut dengan Pola Umak, dan yang lain disebut pola ningkah dan ngulung.

\section{Pemain}

Jumlah pemain pada kesenian Syarofal Anam yaitu 10-16 orang lakilaki, termasuk Hadi 1 orang. Pemain Syarofal Anam aada penelitian ini yaitu terdiri dari 10 orang termasuk Hadi 1 orang. Semua pemain adalah siswa Pondok Pesantren Sabulussalam, mulai 
dari SMP hingga SMA. Mereka biasa menampilkan kesenian Syarofal Anam dalam berbagai acara hiburan seperti acara pernikahan, maulid nabi, dan juga acara akikah.

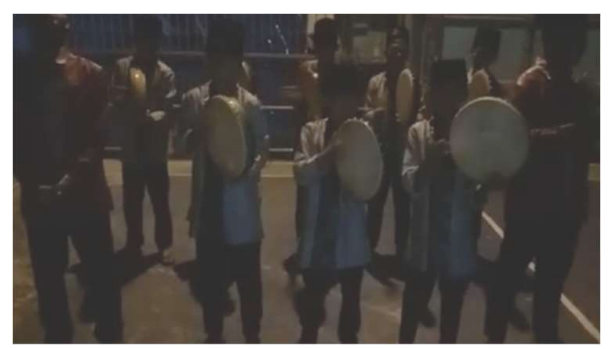

Gambar 5.

Pemain dalam kesenian Syarofal Anam (Dokumen: Nofroza Yelli, 2020)

6. Kostum

Kostum yang digunakan dalam pertunjukan kesenian Syarofal Anam yaitu baju koko, celana Panjang, dan peci.

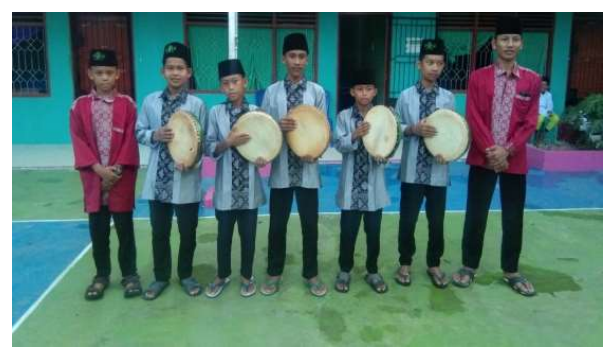

Gambar 6.

Kostum yang digunakan pada pertunjukan Syarofal Anam di Pedestrian Sudirman

(Dokumen: Nofroza Yelli, 2020)

b. PEMBAHASAN

Kesenian Syarofal Anam merupakan salah satu seni tradisi
Sumatera Selatan yang mulai jarang dijumpai ditengah-tengah masyarakat sekarang ini. Kesenian Syarofal Anam biasanya tampil pada acara-acara hiburan seperti acara pernikahan, maulid nabi SAW, dan acara akikah. Isi syair tetap sama yaitu berisikan salawat atas nabi Muhammad SAW. Namun pada penelitian ini, peneliti mencoba memperkenalkan kesenian tradisi Sumatera Selatan kepada masyarakat umum, baik tua ataupun yang muda. Agar kesenian bisa terlestarikan oleh masyarakat saat ini.

Untuk memperkenalkan kesenian ini kepada masyarakat muda, dipilih lokasi yang merupakan salah satu tempat favorit anak muda saat ini yaitu Pedestrian Sudirman. Lokasi ini menjadi tempat berkreasi para anak muda, dan juga seniman. Untuk bisa memikat perhatian para penonton, kelompok musik Syarofal Anam menyajikan lagu yang populer dan tidak asing lagi ditelinga masyarakat saat ini. Salah satunya adalah lagu yang berjudul "Aisyah Istri Rasulullah" dan beberapa lagu Nissa dari grup gambus Sabyan. Dengan membawakan lagu ini, diharapkan masyarakat melirik kembali seni tradisi yang ada Sumatera Selatan. 


$\begin{array}{ll}\text { D. SIMPULAN } & \text { berupa salawat atas nabi, namun juga } \\ \text { Kesenian Syarofal Anam } & \begin{array}{l}\text { terselip beberapa lagu-lagu religi yang } \\ \text { populer saat ini di masyarakat, seperti } \\ \text { biasanya di tampilkan pada acara } \\ \text { pernikahan, maulid Nabi SAW, Akikah, }\end{array} \text { lagu "Aisyah Istri Rasulullah" dan Lagu } \\ \text { dan sebagainya. Lagu yang dibawakan } & \text { "Ya Maulana" dari grup gambus Sabyan. } \\ \text { berisi salawat atas nabi Muhammad } & \text { Pengembangan bentuk Syair } \\ \text { SAW. Pada penelitian ini, kesenian } & \text { lagu pada kesenian Syarofal Anam ini, } \\ \text { syarofal anam di tampilkan di pedestrian } & \text { diupayakan untuk memikat perhatian } \\ \text { Sudirman yang merupakan salah satu } & \text { masyarakat luas terhadap kesenian ini } \\ \text { tempat wisata malam yang ada di kota } & \text { tanpa merubah bentuk asli dari kesenian } \\ \text { Palembang. Tempat ini selalu ramai } & \text { Syarofal Anam. Diharapkan kesenian ini } \\ \text { pengunjung, terumata masyarakat di } & \text { terus dikenal dan dilestarikan ditengah- } \\ \text { sekitar kota Palembang. Dilihat dari } & \text { tengah masyarakat Sumatera Selatan. } \\ \text { Struktur lagu yang dibawakan dalam } & \text { Pengembangan ini juga dengan harapan } \\ \text { kesenian Syarofal Anam ini, terdapat } & \text { generasi muda menyukai kesenian ini } \\ \text { beberapa perbedaan dari biasanya, yaitu } & \text { dan mau belajar untuk mencegah punah } \\ \text { penyajian syair lagu yang dibawakan. } & \text { nya kesenian tradisi khususnya seni } \\ \text { Lagu-lagu yang dibawakan tidak hanya } & \text { tradisi Syarofal Anam. }\end{array}$

\section{DAFTAR PUSTAKA}

Anam, Saiful. 2011. Mudahnya berpikir positif. Jakarta: Visimedia.

Dukut, Ekawati Marhaenny. 2020. Kebudayaan, Ideologi, Revitalisasi dan Digitalisasi Seni Pertunjukan Jawa dalam Gawai. Semarang: Unika Soegijapranata.

Hermansyah dan Zulkhairi. 2014. Transformasi Syair Jauharat At-Tauhid di Nusantara. Denpasar: Pustaka Larasati.

Misral, Dkk. 2014. Musik Etnik di Sumatera Selatan. Palembang: Dinas Pendidikan Provinsi Sumatera Selatan.

Nakagawa, Shin. 2000. Musik dan kosmos: sebuah pengantar etnomusikologi. Jakarta: Yayasan Obor Indonesia.

Rohidi, Tjetjep. R. 2011. Metodologi penelitian Seni. Semarang: Cipta Prima Nusantara. 
Rukmi, Maria Indra. 2005. Penyalinan naskah melayu di Palembang. Jakarta: Universitas Indonesia.

https://www.genpi.co/berita/9117/menikmati-wisata-malam-pedestrian-sudirmanpalembang. Diakses tanggal 20 Juli 2020) 